\title{
Syndromic microphthalmia type 5
}

INSERM

\section{Source}

INSERM. (1999). Orphanet: an online rare disease and orphan drug data base. Syndromic microphthalmia type 5. ORPHA:178364

Syndromic microphthalmia, type 5 is characterized by the association of a range of ocular anomalies (anophthalmia, microphthalmia and retinal abnormalities) with variable developmental delay and central nervous system malformations. 